\title{
Decision Support System for Roof Installation
}

\author{
Daiva MAKUTÉNIENE் ${ }^{1}$, Olga Regina ŠOSTAK ${ }^{1}$, Augustinas MACEIKA ${ }^{2}$ \\ ${ }^{1}$ Department of Engineering Graphics, Vilnius Gediminas Technical University, \\ 11, Saulètekio al. 609 room, LT-10223 Vilnius, Lithuania, \\ daiva.makuteniene@vgtu.lt, olga-regina.sostak@vgtu.lt \\ ${ }^{2}$ Department of Mechanical Engineering, Vilnius Gediminas Technical University, \\ 28, J. Basanavičiaus Street, 1012 room, LT-03224 Vilnius, Lithuania, \\ augustinas.maceika@vgtu.lt
}

\begin{abstract}
The authors of the article carried out a feasibility study of the complex decision support system (DSS) which is designed for a successful roof installation. Analysis was made to examine the created database (DB) of the roof design variants. Delphi technique was used to determine the main parameters and sub-parameters for possible roofing projects variants evaluation and to assess importance and weight of the parameters. After assessment of the complex DSSs creation methodology, parameters used in the system, indicators and the practical aspects of the application, it was planned to create the prototype of the system. For this purpose DSSs of a variety of application fields and their development processes were researched. Based on the research results, the authors proposed the complex DSS model, which enables customers to explore different roof installation projects and inform them about the benefits and costs of the projects being assessed.
\end{abstract}

Keywords: Decision support system, decision making, roof installation, case study, Delphi method.

\section{Introduction}

Application of the complex DSS for roofing activities creates new opportunities to make a more effective decision and to choose the most suitable option, which would align the interests of the customer, architect, and builder.

Key indicators influencing the choice of roofing are balance between quality and cost, design requirements, and roof construction techniques. The most common mistake, in selecting roofing, is decisions after evaluation only of the roofing price per square meter. Indeed, first of all it is worth to count all the construction or renovation costs if one or another roof covering was chosen, only then to compare. Here you need to evaluate everything from the price, which includes the specific elements of the roof structure, roofing with all the necessary accessories and ending with a price of the roofing. Assessing the quality of the roof, durability, and aesthetics, it is also worth to look into the manufacturer's experience guarantee.

According to the authors, after the assessment of the conflicts resolution complexity, the number of participants, the abundance of information and data, in order to perform a successful roofing work it is necessary to have advanced DSS. The system's objective and purpose is to collect, analyse, and visualize the data and processes, after they are submitted for the experts and building customer assessment. Importance of the information visualization was defined in scientific publications of many scientists and there are potential benefits from using visual representations of project interdependence (C.P. Killen (2013)). The system collected various types of data numerical and textual, graphical and logical. Their search and management can be optimized by means of imaging techniques.

According to the T.L., Saaty and H.S. Shih (2009) geometry is necessary to represent the structure for decision making too. They proposed to use new kind of subjective geometry: a graph of a hierarchy or a network, as such a representation makes it easier to visualize and understand the relevant issues and their interactions and enables us to solve the problem with greater efficiency, relevance and confidence.

To improve the roofing projects evaluation by the experts the Delphi method was selected. According to A. Marchais-Roubelat, F. Roubelat (2011), the Delphi method is important to give access to specific forms of knowledge and this knowledge may be characterized according to the type of knowledge sought after, its status, its temporality, and its field of use and the risk of bias that may affect it. The aim is to obtain advice regarding the action to be made within the scope of an aid to decision-making. 
The goal of this work is to make a feasibility study of the complex DSS for roofing modelling. For this purpose DSSs of a variety of application fields were researched and their development tendencies were analysed. Based on the analysis, the authors proposed the prototype model of the complex DSS.

Applied methods - analysis of scientific literature and other information sources, study of the DSSs variants, analysis of its application cases, Delphi approach to establish parameters for evaluation, and the modelling of complex DSS for the roofing.

\subsection{Methodology}

According to F.G. Filip et al. (2014), the steadily increasing interest in the research area of DSS was identified during the period 20102013 and a lot of examples of DSS development methodology was presented in the scientific publications.

X. Luo et al. (2011) concluded that the group DSS can effectively facilitate the implementation of value management in construction briefing. The system allows a client to define and represent his or her requirements with functions and functional performance, to bring forward ideas to achieve the functions, and finally to evaluate and highlight the ideas against the functional performance for further development in design.

D.C. Novak, C.T. Ragsdale (2003) proposed methodology for solving stochastic, multicriteria linear programming problems. J. Gottschlich, O. Hinz (2014) proposed DSS that can support the investor in three different aspects. First, by creating a ranked list, the investor gets advice about the most preferable securities on a specific date. In addition, the system supports the implementation and simulation of strategies based on the computed ranking so that investors can test and explore different approaches to identify promising investment strategies. Once a suitable strategy has been identified, the system can be used to automatically follow a specified strategy day by day and create orders to modify a portfolio. The system's task is to transform crowd votes into actionable share ratings for a given day.

In K. Fagerholt et al. (2010) methodology Microsoft Excel is used for input of case and scenario information to Turbo Router and for output of results from the analysis.

A. Kengpol, P. Neungrit (2014) proposed methodology consists of the prediction modelling and risk assessment analysis. G. Kyriakarakos et al. (2014) methodology approach followed for the implementation of decision support toolkit consists of four discrete stages: parameters (legal/regulative/administrative, financial, technical, social and environmental) investigation, indicators choice, fuzzy cognitive maps implementation, and implementation of the decision support toolkit in a web-platform.

According to L. Yu, K.K. Lai (2011) multiperson multi-criteria group decision making model is composed of six main procedures: to construct the group decision making environment, to select different decision criteria for decision alternative evaluation, to formulate various decision alternatives, to use criteria weight determination methods to determine criteria weights, to give different decision results for every alternative, to aggregate different decision results into a group consensus in terms of the maximum agreement principle. The aggregated group consensus value can be used as a final measurement for the final decision-making purpose.

According to G. Desanctis and R.B. Gallupe (1987), three environmental contingencies are identified as critical to of group decision support systems design: group size, member proximity, and the task confronting the group.

According to the T. Wanderer, S. Herle (2015) decision making is influenced by a multitude of different physical, economic or social criteria with many of them being of spatial nature.

C. Bolchini et al. (2007) proposes a design methodology for very small DB. According methodology the main mobility issues are considered along with data distribution, context awareness is included in the data design issues to allow full exploitation of context-sensitive application functionalities, and the peculiarities of the storage device are taken into account by introducing a logistic phase.

R. Mohemad et al. (2010) proposed a framework of ontological-based extraction for decision support system in order to improve tender assessment process. In order to automate 
the tendering processes, integrating ontology in DSS model seems to be a promising approach.

In D. Tang et al. (2011) paper, a novel method is proposed to generate a belief rule base, which is the basis of the Belief Rule-Base Inference Methodology using the Evidential Reasoning. Due to its capability in dealing with complex reasoning problems under uncertainty, Rule-Base Inference Methodology using the Evidential Reasoning is then applied to assess customer perception risk in a new product development process.

According to J.P. Shim et al. (2002), DSS support process can be enhanced by continued developments in Web-enabled tools, wireless protocols, and group support systems, which can expand the interactivity and pervasiveness of decision support technologies.

E. Dupuit et al. (2007) proposed methodology for decision support approach to manage a refinery wastewater treatment plant by using model of the network.

The consensus support system presented by S. Alonso et al. (2010) aims were to facilitate experts to express their preferences on the alternatives in the problem while maintaining their consistency and to provide easy to understand recommendations in form of simple rules to help them to converge to a solution for the problem with a high level of consensus.

In the H. Konu (2015) study, the Delphi was implemented in order to develop services by involving the customers in the process. Customer ideas and opinions are used in new product and service development even though it has sometimes been found challenging e.g. by criticising that customers do not necessarily know what they want. Two Delphi rounds were used. The first round was used to collect new ideas for different purposes in new service development and these ideas were then analysed and thematic products/product themes were formed by using narrative analysis. During the second round in the comments related to the thematic products, alternative forms or products were suggested.

According to the Đ.T.N. Quyên (2014) the Delhi method stages consist of the Pre-Delphi construction of potential indicators, panel selection and recruitment, data collection and analysis. Data collection and analysis was of three rounds. In Round 1, proposed set of indicators was discussed, in Round 2, experts were asked to rate the level of importance of the indicators using the scale from 0 to 4 . Coefficient of Quartile Variation (CQV) was used to measure the level of consensus among ratings and Coefficient of variation $(\mathrm{CV}=\sigma / \mu)$ was used to measure the extent to which indicators in a factor vary in weights, in Round 3 , the interviews with experts were transcribed, and thematic analysis was applied to analyse the data.

After evaluation of above examined literature, the authors of the article proposed to applied methods for complex DSS system modelling:

1. Alternatives of roofs selection: analysis of all roofs types and the elements of the roofs.

2. Project organization.

3. Customers objects analysis: objects preserved by State; VIP roofs, the average customer orders, cheap and other options.

4. Data Base formation.

5. Establishment of the decision making criterions and system of the parameters creation by using Delphi method.

6. Decision making.

\section{Identification of the parameters}

\subsection{Alternatives of roofs selection: roof types and the elements of the roofs}

As described in one of the widely known handbook by C.G. Ramsey; H.R. Sleeper (2007), about design considerations, roofing generally falls into two broad categories, steep slope and low slope. Selecting the roof assembly is dependent on many factors, as lifecycle cost, reliability, fire-resistance, building height, complexity of the building geometry, etc. The roof selection in information system depends on many parameters and variables textual, logical, esthetical, economical etc. Footpath of the roof depends on main constructions of the building. When designing out a roof, there are certain essential factors that must be considered. These are roof span, roof height or rise, and roof pitch.

The main parameters of the roof are described by geometry and topology depending on the 
type of the roof. Common roof types are shown in the Figure 1.

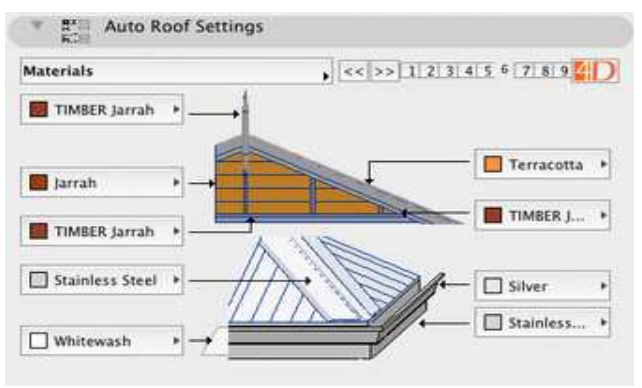

a)

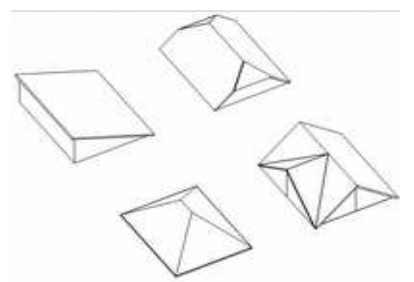

b)

Figure 1. Auto Roof Settings in CAD system (a) and few common roof types (b)

Covering types are very different too. Only a gable roof has minimum four common different types of covering - wood, metal sheets, wave slate and tiles and they have different types of covering by material, geometrical form, etc. Roofing options are generated from the variants of roof profile, the current typical pavement elements in sale, their design features, colours. It is possible to generate specific options, when completely new materials and additionally installed solar panels or solar thermal collectors on a roof will be used. The cost of the project also can be taken into account. Options of chimney decoration, rainwater system, skylights, ventilation equipment, insulation, safety means, and protection from lightning and other items can also be included. They consist of a number of additional options. In order to minimize the flow of information of roof installation project variants, the particular cases under the original user preferences can be generated.

\subsection{Estimation of the separate parameters}

After development of the initial version of the complex DSS for roofing, the idea to use many experts covering communication technique to improve the reasonableness of the decisions was raised. A proposal was adopted to use the Delphi method, which is beneficial for the extraction of a collective opinion of the independent experts. By applying the Delphi method it was planned to clarify the set of valuable parameters and to determine the weights of those parameters. The Delphi method was used to establish the set of parameters to be evaluated by 30 experts. The authors predicted that the Delphi process will be carried out in 3 stages:

1. in the first stage of the survey respondents were inquired and the set of parameters and sub-parameters for assessment was established. For this purpose the professionals who are engaged in the design work, users of the roofs, owners of the projects and the other people who have ideas on the subject were surveyed.

2. during the second stage of the survey respondents were asked to determine the weights of parameters for various categories of the projects. Roof installation project categories were divided into extreme (for very important person (VIP)), protected by the state, expensive, midprice, low-cost items, and the other types of roof installation projects (alternatives).

3. during the third stage respondents were surveyed and the priority positions of the parameters were determined, which was done according to the importance of the roof installation projects for successful implementation and customer satisfaction evaluation (respondents were asked to specify the rank number from 1 to 11). The questionnaire was designed to reconcile opinions of the experts. The results were processed using Kendall concordance coefficient. Kendall's coefficient of concordance $\mathrm{KW}$ was calculated as:

$$
K W=\frac{12\left(\sum_{i=1}^{n}\left(\sum_{k=1}^{m} r_{i, k}-\frac{1}{n} \sum_{i=1}^{n}\left(\sum_{k=1}^{m} r_{i, k}\right)\right)^{2}\right)}{m^{2}\left(n^{3}-n\right)}
$$

where $r_{i, k}$ is given the rank for the object $i$ by the judge number $\mathrm{k}, \mathrm{n}$ - the total number of the objects, and $\mathrm{m}-$ the total number of the judges. If the $\mathrm{KW}$ is 1 , all the survey respondents have assigned the same rank sequence to the list of concerns. If $\mathrm{KW}$ is 0 , then there is no overall trend of agreement among the respondents.

Estimation of the separate parameters for each possible alternative of the roof installation projects can be accomplished by the formula, converting them into $0-100$ points system from the $1-5$ points system: 


$$
F_{h j}=100\left(\frac{V_{h j}-\min _{F}}{\max _{F}-\min _{F}}\right)
$$

where $V_{h j}$ - evaluation of $j$ parameter for the $h$ project (average points assigned by the experts from 1 to 5), $\max _{\mathrm{F}}$-maximum points for $\mathrm{V}_{\mathrm{hj}}$ parameter evaluation (in our case 5 points), $\min _{\mathrm{F}}-$ minimum points for $\mathrm{V}_{\mathrm{hj}}$ parameter evaluation (in our case 1 points). In our case, it was planned that the parameters will be evaluated by 3 experts and in the calculations average points will be used. The total evaluation for each of the possible roof installation project can be done as a weighed average of the separate parameters evaluated by the experts (the $0-100$ points system):

$A_{h}=\frac{\sum_{j} W_{h j} F_{h j}}{\sum_{j} W_{h j}}$ where $W_{h j}$ - is the weight of $j$ parameter for the $\mathrm{h}$ project (weight of the parameter is positive and common for all valued projects of the selected type of the roof and was assigned as average of 30 respondents answers presented from 1 to 5 points).

\section{Indicators Establishment}

After the analysis of implemented roof installation projects and application of the Delphi method for the set of parameters was described, indicators for decision making were established. Since during the implemented project study a lot of parameters were found, but for visualization it was necessary to decrease the amount of information, the subparameters of similar nature were added to the groups and presented in Table 1. The parameters were entered into Excel programme

Table 1. Indicators for decision making

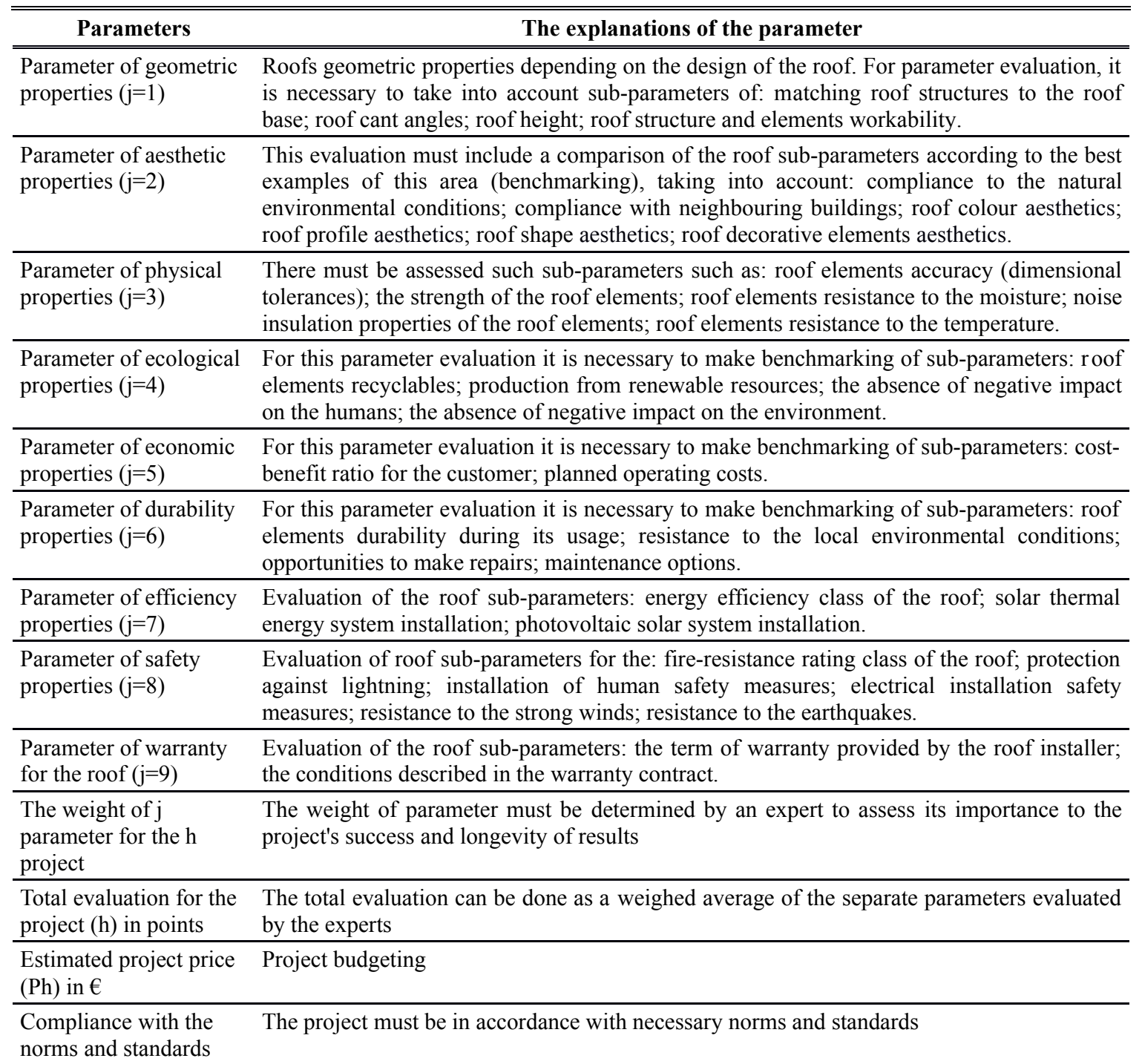


for many variants of the roof design generation. After the second stage of the Delphi survey, it was found that thirty experts distributed weights for various roofing projects as presented in Table 2. As during the third stage of the Delphi method it was found that Kendall concordance coefficient for the selected parameters was $\mathrm{KW}=0.14$, and this value indicates that the experts opinion of the parameters priorities are quite different, it was decided to engage a few experts, to have more accurate results. The average weight in various roofing projects is quite different; especially it is low for cheap roof installation projects.

\section{DSS Design}

The authors of the article established that the efficient use of information requires a developed information network, which is connects architects, experts and new roof construction or reconstruction customers. This network is a basis of the complex DSS thanks to the appropriate dissemination of knowledge through visualization tools.

The conception of the complex DSS design is presented in Figure 2. The final decision about the choice to implement appropriated variant

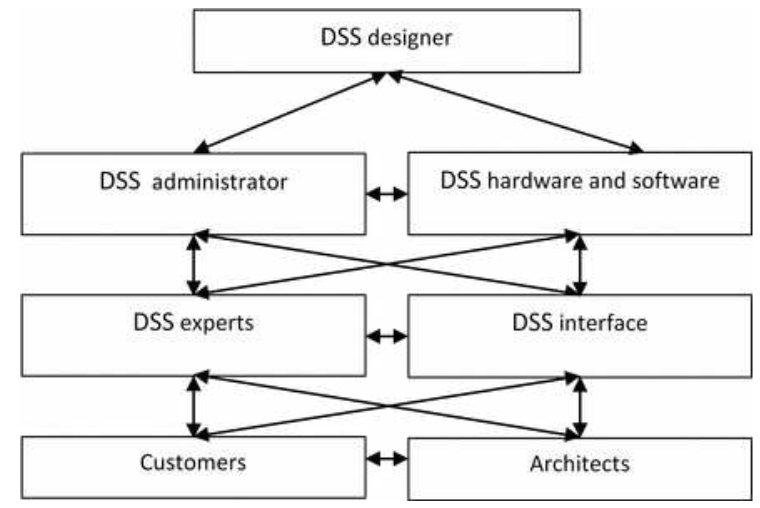

Figure 2. Complex DSS design

Table 2. The average weight of parameters

\begin{tabular}{|c|c|c|c|c|c|c|}
\hline \multirow[b]{2}{*}{ Parameters } & \multicolumn{6}{|c|}{ The weight of parameter for the roof installation projects $\left(W_{\mathrm{hj}}\right)$} \\
\hline & $\begin{array}{c}\text { Extreme } \\
\text { (VIP) roof } \\
\text { installation } \\
\text { projects }\end{array}$ & $\begin{array}{c}\text { Protected by } \\
\text { the state } \\
\text { objects roof } \\
\text { installation } \\
\text { projects }\end{array}$ & $\begin{array}{c}\text { Expensive } \\
\text { roof } \\
\text { installation } \\
\text { projects }\end{array}$ & $\begin{array}{c}\text { Mid-price } \\
\text { (economic) } \\
\text { roof } \\
\text { installation } \\
\text { projects }\end{array}$ & $\begin{array}{c}\text { Low-cost } \\
\text { (cheap) roof } \\
\text { installation } \\
\text { projects }\end{array}$ & $\begin{array}{c}\text { The other } \\
\text { type of roof } \\
\text { installation } \\
\text { projects } \\
\text { (alternatives) }\end{array}$ \\
\hline $\begin{array}{l}\text { Parameter of } \\
\text { geometric } \\
\text { properties }(j=1)\end{array}$ & 4,57 & 4,47 & 4,23 & 3,77 & 3,47 & 4,22 \\
\hline $\begin{array}{l}\text { Parameter of } \\
\text { aesthetic } \\
\text { properties }(\mathrm{j}=2)\end{array}$ & 3,97 & 4,33 & 4,5 & 2,7 & 2,3 & 3,52 \\
\hline $\begin{array}{l}\text { Parameter of } \\
\text { physical } \\
\text { properties }(\mathrm{j}=3)\end{array}$ & 4,6 & 4,1 & 4,27 & 3,63 & 2,97 & 4,17 \\
\hline $\begin{array}{l}\text { Parameter of } \\
\text { ecological } \\
\text { properties }(\mathrm{j}=4) \\
\end{array}$ & 3,1 & 3,57 & 3,7 & 2,47 & 1,87 & 3,04 \\
\hline $\begin{array}{l}\text { Parameter of } \\
\text { economic } \\
\text { properties }(j=5)\end{array}$ & 3,67 & 3,83 & 4,07 & 4,27 & 4,03 & 4,26 \\
\hline $\begin{array}{l}\text { Parameter of } \\
\text { durability } \\
\text { properties }(j=6)\end{array}$ & 4,17 & 4,33 & 4,27 & 3,37 & 3,1 & 3,52 \\
\hline $\begin{array}{l}\text { Parameter of } \\
\text { efficiency } \\
\text { properties }(j=7)\end{array}$ & 4,03 & 3,77 & 4 & 3,3 & 2,8 & 3,91 \\
\hline $\begin{array}{l}\text { Parameter of } \\
\text { safety } \\
\text { properties }(\mathrm{j}=8)\end{array}$ & 4,53 & 4,33 & 4,37 & 3,87 & 3,7 & 4,43 \\
\hline $\begin{array}{l}\text { Parameter of } \\
\text { warranty for } \\
\text { the roof }(j=9)\end{array}$ & 4,07 & 4,17 & 4,2 & 3,67 & 3,3 & 4,22 \\
\hline
\end{tabular}




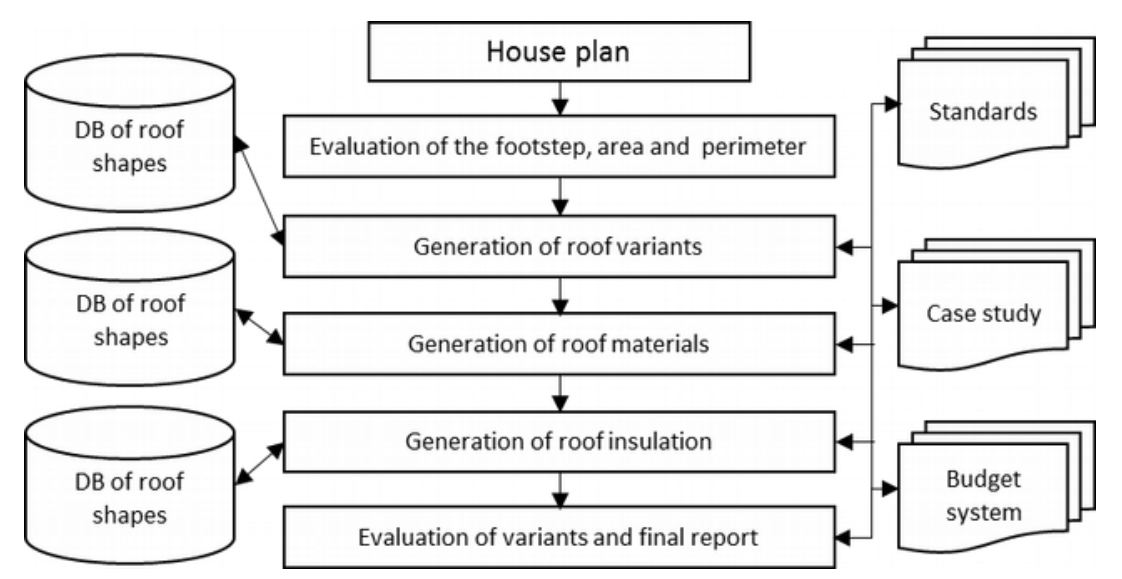

Figure 3. Some steps of decision making process for roofing

of the roof installation project must be done by the customer.

\subsection{Development of the system}

For the decision-making support a comprehensive DB consisting of the various roofing types and configurations on the basis of Microsoft Excel programme was developed. Each option has been connected to the costing sub-systems and final experts' evaluation subsystem as presented in Figure 3. The customer of the roof installation project can view a variety of appropriate options, which have been already evaluated by experts, and to decide which one to choose. If none of the proposed options satisfies the customer, then the new stage for potential new options generating and evaluation can be implemented. Table 3 presents an example of evaluation of the small apartment house with an option of a gable roof and clay tiles. Parameter scoring is based on the subjective thinking of the experts and the quantitative estimation of the project budget. Some of the rateable parameters are composed of several smaller sub-parameters, which must be evaluated and worked out from the average and then entered into the table. If any of sub-parameters are assessed as 1 point from 5 , it can have a greater impact on the final parameter evaluation. After the implementation of the selected project option, the assessment of its success must be carried out and a further review must be done on exactly how close to the project's final results the experts' assessment was. Then, the data is stored in a DB for results analysis and for the feedback assurance.

Table 3. Example of the roof installation project parameters evaluation by the experts of the DSS

\begin{tabular}{lccc}
\hline \multicolumn{1}{c}{$\begin{array}{c}\text { Project type } \text { - average prices (economic) } \\
\text { roof installation }\end{array}$} & \multicolumn{2}{c}{ Project No. GTCA0101 evaluation } \\
\cline { 2 - 4 } & Weight & Evaluation of parameter \\
\hline \hline Evaluated parameters & $\mathrm{W}_{1 \mathrm{j}}$ & $\mathrm{V}_{1 \mathrm{j}}$ & $\mathrm{F}_{1 \mathrm{j}}$ \\
Parameter of geometric properties $(\mathrm{j}=1)$ & 3.77 & 4.33 & 83.33 \\
Parameter of aesthetic properties $(\mathrm{j}=2)$ & 2.7 & 4.00 & 75.00 \\
Parameter of physical properties $(\mathrm{j}=3)$ & 3.63 & 4.33 & 83.33 \\
Parameter of ecological properties $(\mathrm{j}=4)$ & 2.47 & 3.67 & 66.67 \\
Parameter of economic properties $(\mathrm{j}=5)$ & 4.27 & 4.33 & 83.33 \\
Parameter of durability properties $(\mathrm{j}=6)$ & 3.37 & 4.33 & 83.33 \\
Parameter of efficiency properties $(\mathrm{j}=7)$ & 3.3 & 3.67 & 66.67 \\
Parameter of safety properties $(\mathrm{j}=8)$ & 3.87 & 4.33 & 83.33 \\
Parameter of warranty for the roof $(\mathrm{j}=9)$ & 3.67 & 4.33 & 83.33 \\
Total evaluation for the project $(\mathrm{h})$ in points & & $\mathrm{A}_{1}$ & 79.51 \\
Estimated project price $($ Ph) in $€$ & & $\mathrm{P}_{1}$ & 15910 \\
Compliance with the norms and standards & & & Yes \\
\hline
\end{tabular}




\section{System Application Peculiarities}

The results of the roof installation project implementation will depend on the conditions existing in the system environment. During the implementation of the project, the construction organization team must be in contact with the architects from the designing organization and the customer. After studies of the houses roofs project implementation, it was found that the larger problems do not arise when using bitumen tiles. However, much worse results were observed in the analysis of clay-tiled roofs. From the above presented case study, it is possible to envisage that the choice of building organizations for project implementation is a sensitive issue. Experts should gather a list of potential candidates and to offer for the customer only a well proven foreman. The DB should be compiled of the disputable problematic cases and solutions made. Decision support DB provides a list of well proven construction companies, as well as contentious and problematic situations analysis. Only full involvement of the roof installation project participants and their efforts to ensure good quality of the work, which meets the customer's requirements, can lead to success. After the review of publications about the application of the similar systems (S. Rahman et al. (2012) and A. Spanaki et al. (2011)), it can be said, that the work to improve information systems in the field of construction can have a great outcome.

\section{Conclusions and suggestions}

The analysis of the literature and case study results showed that there are many of engineering and management activities in decisions making process, and that these activities must be provided with the relevant information and judgment. As shown by the bitter experience, is not always possible to rely on promises from the companies offering their services in the field of roofing installation. Customer expects to have high quality product for the paid money, but without having adequate competence, may need to invite experts to identify the effects of the low-skilled work results. Subjective geometry is important to visualize the DSS elements. Information subsystem of DSS must provide information about the regulations, companies and manufacturers, and also structured information about roof structures, pavement types, work rates, that would make it possible to more effectively analyse the data if it is constantly updated, assessing the changing environmental conditions. After the Delphi method of three stages application, it was found that the opinion of the experts is very different when evaluation of roof parameters is going on. It is necessary to engage a few experts for having more accurate results, and to take the average from the evaluation points. The complex DSS for specific activities like roofing can be a start line for innovation in doing improvements and in making good decisions for sustainable upgrade. The customer, not being an expert in the researched field using a DSS has an access to information source for better quality decisions or for checking of the rationality of the proposed project.

\section{REFERENCES}

1. ALONSO, S., E. HERRERA-VIEDMA, F. CHICLANA, F. HERRERA, A Web based Consensus Support System for Group Decision Making Problems and Incomplete Preferences, Journal of Information Sciences, vol. 180, no. 23, 2010, pp. 4477-4495.

2. Auto Roof Settings in ArchiCAD, [cited 15 March 2015]. Available from Internet: http://4dlibrary.com.au/library/wpcontent/gallery/auto-roofing-gallery/.

3. BOLCHINI, C., F. A. SCHREIBER, L. TANCA, A Methodology for a Very Small Data Base Design, Journal of Information Systems, vol. 32, no. 1, 2007, pp. 61-82.

4. DESANCTIS, G., R. B. GALluPE, A Foundation for the Study of Group Decision Support Systems, Journal of Management science, vol. 33, no. 5, 1987, pp. 589-609.

5. DUPUIT, E., M. F. POUET, O. THOMAS, J. BOURGOIS, Decision Support Methodology using Rule-based Reasoning Coupled to Non-parametric Measurement for Industrial Wastewater Network Management, Journal of Environmental Modelling \& Software, vol. 22, no. 8, 2007, pp. 1153-1163. 
6. FAGERHOLT, K., M. CHRISTIANSEN, M. Ł. HVATTUM, T. A. V. JOHNSEN, T. J. VABØ, A Decision Support Methodology for Strategic Planning in Maritime Transportation, Journal Omega, vol. 38, no. 6, 2010, pp. 465-474.

7. FILIP, F. G., A.-M. SUDUC, M. BIZOI, DSS in Numbers, Technological and Economic Development of Economy, vol. 20, no. 1, 2014, pp. 154-164.

8. GOTTSCHLiCH, J., O. HINZ, A Decision Support System for Stock Investment Recommendations using Collective Wisdom, Journal of Decision Support Systems, vol. 59, 2014, pp. 52-62.

9. KENGPOL, A., P. NEUNGRIT, A Decision Support Methodology with Risk Assessment on Prediction of Terrorism Insurgency Distribution Range Radius and Elapsing Time: An Empirical Case Study in Thailand, Journal of Computers \& Industrial Engineering, vol. 75, 2014, pp. 55-67.

10. KILlen, C. P., Evaluation of Project Interdependency Visualizations through Decision Scenario Experimentation, International Journal of Project Manag., vol. 31 , no. 6 , 2013, pp. 804-816.

11. KONU, H., Developing Nature-based Tourism Products with Customers by Utilising the Delphi Method, Journal of Tourism Management Perspectives, vol. 14, 2015, pp. 42-54.

12. KYRIAKARAKOS, G., K. PATLITZIANAS, M. DAMASIOTIS, D. PAPASTEFANAKIS, A Fuzzy Cognitive Maps Decision Support System for Renewables Local Planning, Journal of Renewable and Sustainable Energy Reviews, vol. 39, 2014, pp. 209-222.

13. LUO, X., G. Q. SHEN, S. FAN, X. XUE, A Group Decision Support System for Implementing Value Management Methodology in Construction Briefing, International Journal of Project Man., vol. 29, no. 8, 2011, pp. 1003-1017.

14. MARCHAIS-ROUBELAT, A., F. ROUBELAT, The Delphi Method as a Ritual: Inquiring the Delphic Oracle, J. of Technological Forecasting \& Social Change, vol. 78, 2011, pp. 1491-1499.

15. MOHEMAD, R., A. R. HAMDAN, Z. A. OTHMAN, N. M. M. NOOR, Decision Support Systems (DSS) in Construction Tendering Processes. International Journal of Computer Science Issues, vol. 7, issue 2, no 1, 2010, pp. 35-45.

16. NOVAK, D. C., C. T. RAGSDALE, A Decision Support Methodology for Stochastic Multi-Criteria Linear Programming using Spreadsheets, Journal of Decision Support Systems, vol. 36 , no. 1, 2003, pp. 99-116.

17. QUYÊN, Đ. T. N., Developing University Governance Indicators and Their Weighting, Procedia - Social and Behavioral Sciences, vol. 141, 2014, pp. 828-833.

18. RAHMAN, S., H. ODEYINKA, S. PERERA, Y. BI, Product-cost Modelling Approach for the Development of a Decision Support System for Optimal Roofing Material Selection, Journal of Expert Systems with Applications, vol. 39, no. 8,2012 , pp. $6857-6871$.

19. RAMSEY, C. G., H. R. SLEEPER, Architectural Graphics Standards, eleventh edition, The American Institute of Architects, Wiley \& Sons, Inc., 2007.

20. SAATY, T. L., H. S. SHIH, Structures in Decision Making: On the Subjective Geometry of Hierarchies and Networks, European Journal of Operational Research, vol. 199, no. 3, 2009, pp. 867-872.

21. SHIM, J. P., M. WARKENTIN, J. F. COURTNEY, D. J. POWER, R. SHARDA, C. CARLSSON, Past, Present, and Future of Decision Support Technology, Journal of Decision support systems, vol. 33, no. 2, 2002, pp. 111-126.

22. SPANAKI, A., T. TSOUTSOS, D. KOLOKOTSA, On the Selection and Design of the Proper Roof Pond Variant for Passive Cooling Purposes, Journal of Renewable and Sustainable Energy Reviews, vol. 15(8), 2011, pp. 3523-3533.

23. TANG, D., J. YANG, K. CHIN, Z. S. Y. WONG, X. LIU, A Methodology to Generate a Belief Rule base for 
Customer Perception Risk Analysis in New Product Development, Journal of Expert Systems with Applications, vol. 38, no. 5, 2011, pp. 5373-5383.

24. WANDERER, T., S. HERLE, Creating a Spatial Multi-criteria Decision Support System for Energy Related Integrated Environmental Impact Assessment,
Journal of Environmental Impact Assessment Review, vol. 52, 2015, pp. 2-8.

25. YU, L., K. K. LAI, A Distance-based Group Decision-making Methodology for Multi-person Multi-criteria Emergency Decision Support, Journal of Decision Support Systems, vol. 51, no. 2, 2011, pp. 307-315. 